Published as: Ooms, K., De Maeyer, P., De Wit, B., Maddens, R., Nuttens, T., Van de Weghe, N., Vervust, S. (2015). Design and use of web lectures to enhance GIS teaching and learning strategies: the students' opinions. Cartography and Geographic Information Science, vol. 42 (3): 271-282. 


\title{
Design and use of web lectures to enhance GIS teaching and learning strategies: Students' opinions
}

\author{
Kristien Ooms*, Philippe De Maeyer*, Bart De Wit*, Ruben Maddens*, \\ Timothy Nuttens*, Nico Van de Weghe*, Soetkin Vervust* \\ *Department of Geography, Ghent University, Krijgslaan 281 (S8), 9000 Ghent, Belgium \\ \{Kristien.Ooms; Philippe.DeMaeyer; Bart.DeWit; Timothy.Nuttens; NicoVandeWeghe; \\ Soetkin.Vervust\}@UGent.be;Ruben.Maddens@GMail.com
}

Corresponding author: Kristien Ooms

\begin{abstract}
The goal of this research is to design, use and evaluate a set of weblectures, specifically tailored to the needs of students in higher education who follow GIS-related courses. Since education in GIS includes theoretical concepts and practical experience, these teaching strategies will both be implemented in the weblectures. The User Centered Design approach is used in the design process to increase the acceptance of the weblectures and the motivation to use them: perceived usefulness and ease of use. The results show that the students appreciate the initial set of weblectures, but that they need to be motivated more to use them (especially when theoretical topics are covered). Students still value the 'traditional' face-to-face lectures and see the weblectures as an ideal complement.
\end{abstract}

\section{Introduction}

Teaching GIS to students in higher education involves a delicate balance between theoretical lectures and practical exercises. Students have to possess a strong theoretical background in Geographic Information Systems (i.e., data management, data structures, analyses, visualization, etc.) and in essential concepts from related disciplines (e.g., cartography, informatics, etc.). Over the years, teaching and learning strategies have evolved in both geography and higher education. Most recently, these evolutions can be linked to technological advancements, including the growing use of the Internet (e.g. Ward \& Newlands 1998; Rafaeli et al. 2004; Day et al. 2005; Ketterl et al. 2009). Because GIS is linked to technological advancement, it is obvious to implement Internet-use as a teaching strategy in both theoretical and practical sessions. Recently, some initiatives have been undertaken in this regard (Frigerio \& van Westen 2010; Harvey \& Kotting 2011; McMaster et al. 2011), but the overall application of the Internet to GIS education is still underdeveloped. This paper analyzes the applicability of integrating new technological advancements into GIS teaching strategies. Based on previous research in this field, the following Research Questions (RQ) will be addressed:

1. Do students appreciate the use of web lectures in their curriculum?

2. Do students find that web lectures can replace "traditional" lectures?

3. How do students use web lectures?

4. Do students need to be motivated to use web lectures? 
The next sections will describe online teaching strategies and the context in which they can be successfully implemented.

\subsection{An online teaching and learning strategy}

Today, the Internet is widely available, and most universities and high schools have their own online learning platforms on which teachers can place course content that allows students to discuss with each other, to submit assignments, etc. (Chen et al. 2010). In this context, teaching strategies, such a blended learning, distance learning, and web lectures can be used. In distance learning there is almost no contact between teacher and student; everything is organized online. In blended learning, face-to-face lessons are combined with other techniques, including web lectures. This is sometimes referred to as "near-distance" or "hybrid distance" courses (Roberts \& Dyer 2005b; Chen et al. 2010).

Web lectures come in many forms and are sometimes referred to as lectures on the web or multimedia lectures (Dori et al. 2003; Rafaeli et al. 2004; Ketterl et al. 2009). They usually consist of a combination of video, audio, and presentation slides (e.g., PowerPoint) streamed over the web (Day 2008). Web lectures can be created at minimum cost by recording a traditional live lecture and placing it online (Ketterl et al. 2009). Other authors recommend recording lectures out of class in order to keep them short (20-25 minutes maximum) or by splitting them up into multiple recordings (Day et al. 2005; Day \& Foley 2006). Tiellet et al. (2010) evaluated a hyper-video environment in which web lectures are used to demonstrate surgical procedures to veterinary students. Software demonstrations and simulations can also be included in these online videos (Poindexter \& Heck 1999). Although these latter examples are not traditional lectures, all online videos that present course information (e.g., lectures, demonstrations, simulations) will be referred to as web lectures in this article.

While some authors are convinced that web lectures will inevitably be implemented in higher education (Garrison \& Kanuka 2004), others question their benefit to students (e.g. Eveland \& Dunwoody 2001; Bernard et al. 2004; Sitzmann et al. 2006; Clark 2009; Chen et al. 2010). The benefits of web lectures are detailed in the next section.

\subsection{Implementation of web lectures}

Previous research revealed that students learn better from active or hands-on learning activities than in passive presentations of information, such as traditional lectures (Dale 1969; Parkinson et al. 2003; Day et al. 2005; Chandler et al. 2013; Lee et al.,2013). This view can be translated into a pyramid form (e.g., the Learning Pyramid), which has the traditional lecture on top and "hands-on practice" near the bottom (see Figure 1). Audiovisual input falls between these two options, which suggests that students watching web lectures should perform better than those attending traditional lecture (Dale 1969; Day et al. 2005; Day \& Foley 2006). 


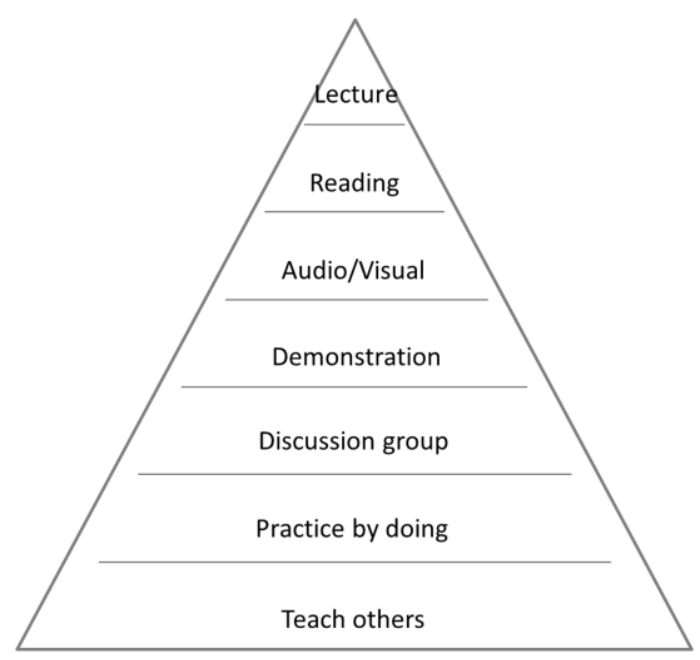

Figure 1. The Learning Pyramid, based on Day et al. (2005).

The best outcomes have been observed when web lectures were used in a hybrid setting, the so-called "blended learning" (Chen et al. 2010). In blended learning there is still face-to-face contact between the teacher, students and other students. This "teach others" aspect is also a crucial social element of the learning process. When web lectures are used as an addition to traditional lectures, more in-class time can be spent on discussions and feedback which are more active teaching activities (Calverley et al. 1998; Rafaeli et al. 2004; Day et al. 2005; Day \& Foley 2006). This factor (the combination of web and traditional lectures) is evaluated in RQ 2 and RQ 3. A number of researchers found that this resulted in higher student scores on evaluations (Day \& Foley 2006). This blended learning approach reduces the amount of time teachers require for a given class, particularly in lecture preparation and delivery. Additional time is needed to prepare and record web lectures; however, web lectures can be reused with minimal effort and cost (Day and Foley, 2006). Twigg $(1999,2003)$ calculated that institutions could reduce their costs by an average of 40 percent by introducing online learning.

Roberts and Dyer (2005a) investigated the effects of user characteristics (e.g. learning styles) on the effectiveness of web lectures and distance learning. Their research did not find any.

Twigg $(2001,2003)$ identified a number of key elements that should be considered in an online environment that would improve students' learning These include an initial assessment of the student's skills, using appropriate and varied interactions, individualized study plans; continuous assessment to provide feedback; and providing interactive learning materials and activities (Roberts \& Dyer 2005b).

Day et al. (2005) learned important lessons from their research project in which web lectures had been used. They emphasized that the creation of web lectures should not be expensive or time consuming. They found that web lectures are not suitable for use in groups. Day et al. (2005) found the use of web lectures is economically attractive because they can reduce the number of in-class meetings. They recommend using web lectures before class, which would leave more in-class time for active learning. Students tend to like this idea but admit that one needs to be strongly motivated to watch web lectures. Other authors also 
mention that a higher level of self-discipline is required when using web lectures (Moses et al. 2002; Day et al. 2005; Day \& Foley 2006). This can be linked to RQ 4 formulated above.

Furthermore, the students' willingness to watch the lectures cannot be separated from their general perception of the lectures (Allen et al. 1996; M. G. Lee 2001). Some authors found that when students enjoyed the web lectures, they learned as much or even more compared to when they did not enjoyed them (Moses et al. 2002; Day et al. 2005; Day \& Foley 2006) because they were more accepting of the lectures and were therefore more motivated to use them (Calverley et al. 1998; Eveland \& Dunwoody 2001; Roberts \& Dyer 2005b). This factor (perception of the web lectures) can be linked to RQ 1 .

Liu et al. (2009) discussed the Technology Acceptance Model in relation to e-learning technology. They found that the users' attitude towards the technology or system was determined by both the perceived ease of use (PEU) and perceived usefulness (PU) (Davis et al. 1989). These latter important elements will be considered in the construction of usercentered web lectures.

\subsection{User-centered web lectures}

The terms "ease of use" and "usefulness" are closely linked with usability. The usability of a certain product is defined as "the extent to which a product can be used by specified users to achieve specified goals with effectiveness, efficiency and satisfaction in a specified context of use" (ISO 9241-11 ,Earthy et al. 2001, p. 554). To create more usable products with a higher perceived ease of use or usefulness, it is important to implement a User-Centered Design-life cycle during the web lectures' design phase.

The User-Centered Design (UCD) is a method that originated in the field of software development (e.g. Nielsen 1993). In this method, the end user of the product is involved in every step of its development, from the initial prototype to the end product. Because the user evaluates the product at different stages in the development, the product can be adjusted to the users' needs at a lower cost, thus creating products that are more usable or user friendly.

Because the students' perceived ease of use and usefulness are important elements in the acceptance of web lectures, it is crucial to consider the usability of the products during their design. Consequently, it is essential that students be involved in the development of web lectures.

The aim of this paper is to present a crucial step in the development of a collection of web lectures, tailored to the needs of students in higher education, and intended to teach GIS more effectively on a theoretical and practical level. To reach this goal, the design of the web lectures was based on User-Centered Design principles. An initial set of web lectures (i.e., a prototype) was developed, which was then evaluated by the end users (i.e., students). The qualitative study also gathered information about the student's requirements for web lectures. This information can significantly improve usability but is often neglected in the development of products and in the geo-domain (van Elzakker \& Wealands 2007).. In the following section, the construction of prototype web lectures for students taking GIS courses at the Department of Geography at Ghent University in Belgium is described. Next, the results of the analysis of student feedback are discussed. These findings reported here can be used to create web lectures tailored to students' needs. 


\section{Initial set of web lectures}

A set of web lectures was created for three different GIS-related topics. Two were (practical) software demonstrations and one was a theoretical subject:

1. Demonstrations in Quantum GIS

2. Demonstrations in AutoCAD

3. Theory on map projections and coordinate systems

Demonstrations in Quantum GIS (or QGIS) were initially created because a rather large group of students (on average 75 students each year with different knowledge) tend to take the GIS course in the first semester. The practical sessions take place in smaller PC rooms, which means they have to be repeated several times. Using web lectures with software demonstrations, students were encouraged to prepare exercises at home and come to lab sessions prepared to solve problems. As a consequence, this type of web lecture replaced the live in-class demonstrations, but interaction with the teacher was still possible. The idea was the same as suggested by Calverley et al. (1998), Day and Foley (2006), (Day et al. 2005) and Rafaeli et al. (2004): more in-class time can be spent on individual guidance and active learning if web lectures replace in-class teacher presentations. Furthermore, students could process the demonstrations at their own pace, which helps to address the differences in students' knowledge. The demonstrations in AutoCAD were made with similar goals --to be able to compress classical demonstrations and to provide better feedback to individual students.

The topic of the initial theoretical set of web lectures-Map Projections and Coordinate Systems - was selected based on course materials (De Maeyer et al. 2012; Antrop et al. 2013; De Maeyer et al. 2013; De Maeyer \& Ooms 2013) for the Bachelor and Master's programs. This topic is taught in both the Bachelor's and Master's program. Students consider the topic difficult but because it is an important part of the curriculum it was decided to use it as a complement to live lectures, or, as a refresher material in the advanced classes. Table 1 gives an overview of the courses in which this initial set of web lectures can be useful.

Table 1. Overview of the courses delivered via web lectures.

\begin{tabular}{|c|c|c|}
\hline Topic & Course & Students \\
\hline Demos AutoCad (TI) & Applied Informatics (AI) & $\begin{array}{l}2^{\text {nd }} \text { Ba Geography and } \\
\text { Geomatics }\end{array}$ \\
\hline \multirow{6}{*}{ Demos QGIS (GIS) } & \multirow{6}{*}{$\begin{array}{l}\text { Geographic Information } \\
\text { Systems (GIS) }\end{array}$} & $2^{\text {nd }} \mathrm{Ba}$ Geography \\
\hline & & $\begin{array}{l}2^{\text {nd }} \text { Ba Geography and } \\
\text { Geomatics }\end{array}$ \\
\hline & & $3^{\text {rd }}$ Ba Archaeology \\
\hline & & Ma Biology \\
\hline & & Ma Urban Planning \\
\hline & & Ma Architecture \\
\hline \multirow{2}{*}{$\begin{array}{l}\text { Map Projections and } \\
\text { Coordinate Systems (KC) }\end{array}$} & \multirow{2}{*}{$\begin{array}{l}\text { Introduction Geomatics } \\
\text { (IG) }\end{array}$} & $1^{\text {st }}$ Ba Geography \\
\hline & & $2^{\text {nd }}$ Ba Archaeology \\
\hline
\end{tabular}




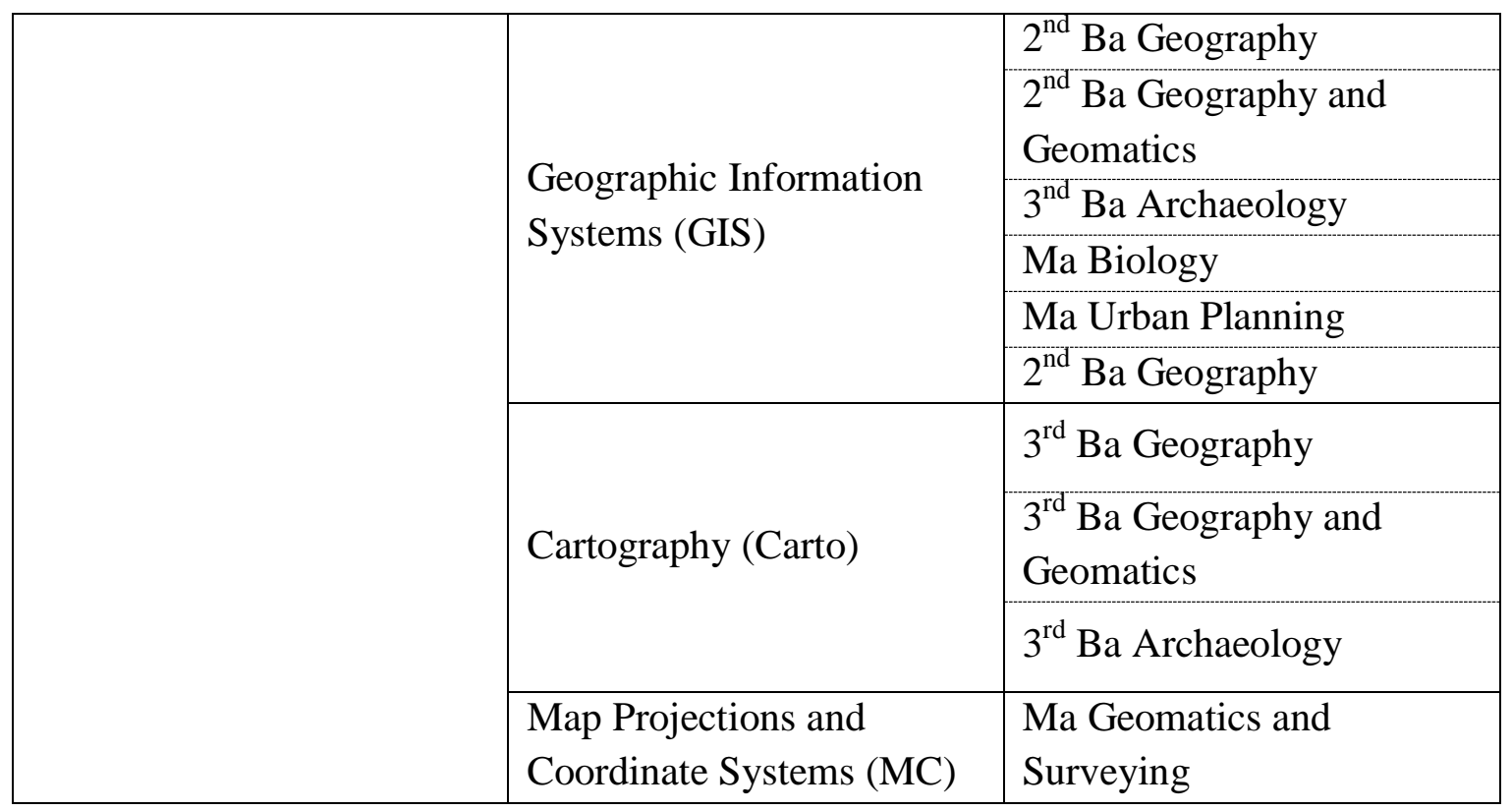

\subsection{Hardware and software}

As mentioned by Day et al. (2005), web lectures can be created with little time and money. We purchased the required material and recorded the web lectures in-house. Figure 2 shows the office where the recording took place. The hardware we used included a desktop PC, a high-definition Webcam, a microphone or headset, and a black screen (i.e., the recorded background behind teacher).

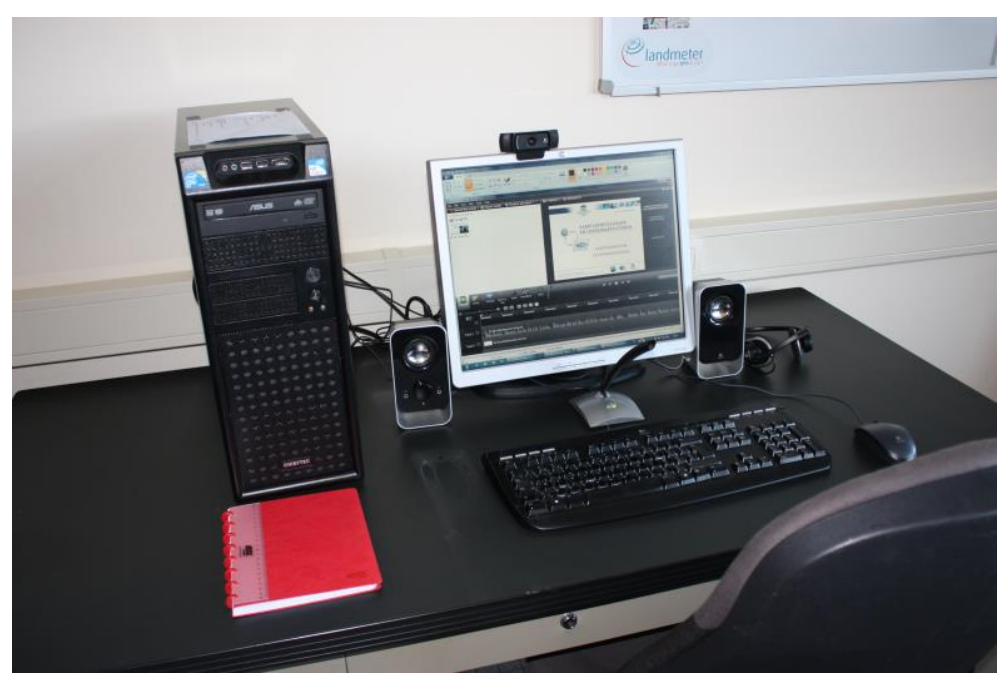

Figure 2. Set-up to record web lectures.

We used Camtasia Studio, a software which allows recording on on-screen activity, editing the contents and sharing the resulting video on nearly any device. Figure 3 shows the software being used to edit one of the videos for Map Projections and Coordinate Systems (MC). 


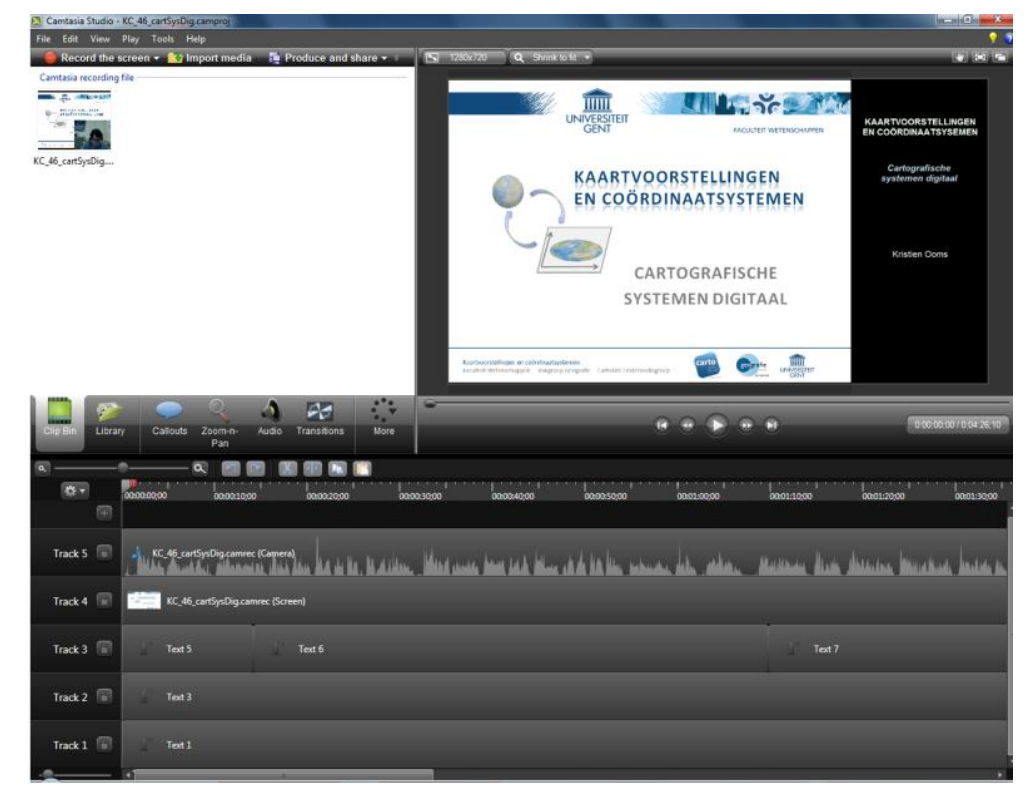

Figure 3. Screenshot of Camtasia Studio.

\subsection{Structure of the web lectures}

All web lectures were recorded in the same 16:9 format with a resolution of $1280 \times 720$ pixels. Only the demonstrations for the QGIS show the teacher in the lower right corner (see Figure 4(a)). The demonstrations for AutoCAD and the theoretical web lectures do not visualize the teacher; only audio is overlaid (see Figure 4(b)). Visualizing the teacher's head increases the size of the video, but because the videos are short, this effect is limited. Bandwidth is also less of an issue in today's Internet based society. Web lectures with theoretical topics all have the same form. The slides are presented in a 12:9 format on the left side of the screen. On the right side is a banner of 4:9 which contains the title of the main topic, the title of the web lecture and the name of the teacher. This first slide also shows the title of the main topic and the title of the web lecture. The same layout for the slides is applied in every video (see Figure 4 (c)).

In accordance with Day's (2008) recommendations, the web lectures were kept short to retain students' attention. Basing his recommendations on a combination of findings in psychology, physiology and student feedback Day proposed 20 minutes as a good length for web lectures. We opted for shorter videos to even diminish this length to be able to distinguish between smaller topics, facilitating the selection of the appropriate web lecture for the students. Our QGIS demonstrations last 5-10 minutes, the AutoCAD demonstrations are somewhat longer at nearly 10 minutes on average. The majority of the theoretical web lectures take less than 5 minutes, with 5-10 slides each. Some "theoretical" web lectures were recorded twice--a simplified version for students in the lower grades and those preparing for advanced courses and an in-depth version intended for students in higher grades. All videos are in Dutch, the official language at Ghent University and the native language of most students enrolled at the Department of Geography. 


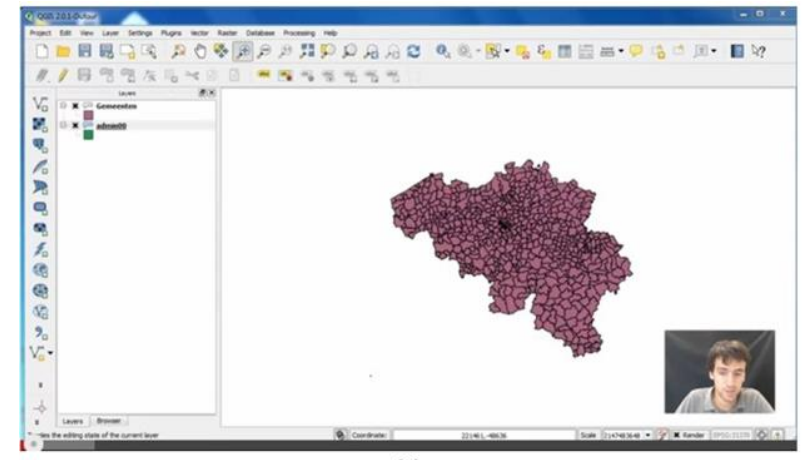

(a)

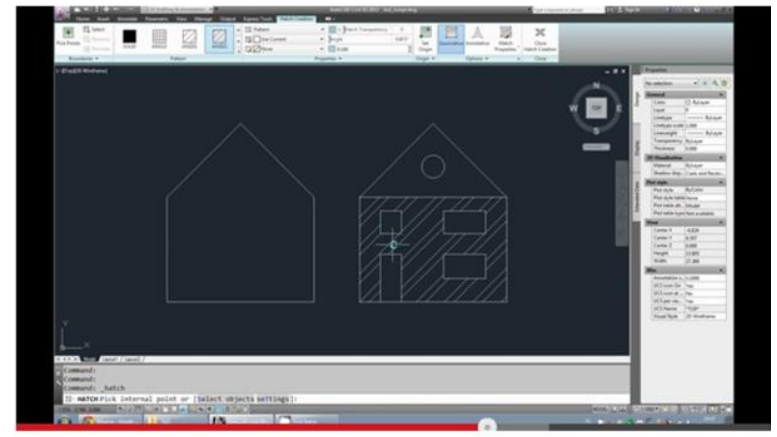

(b)

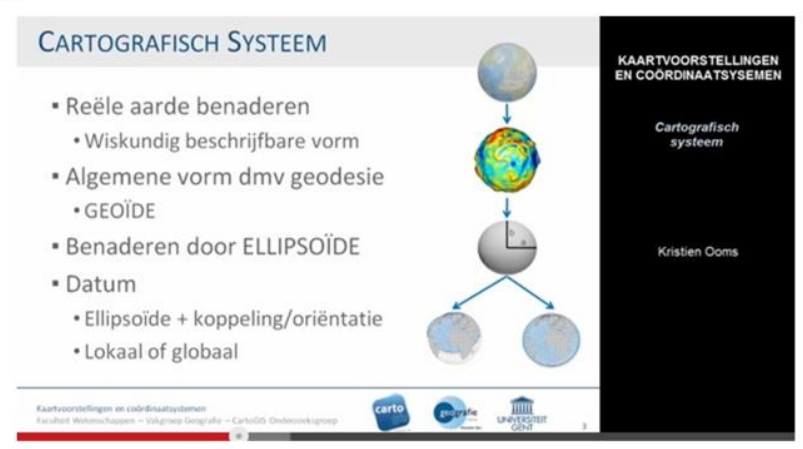

(c)

Figure 4. Screenshots of three types of web lectures (a) QGIS demo; (b) AutoCAD demo; (c) theory on map projections and coordinate systems.

\subsection{Disseminating the web lectures}

The web lectures were made available on YouTube with public visibility (e.g. Ketterl et al. 2009). This medium was chosen because anyone can access the videos from anywhere. This could also be a help for secondary school students to choose a career path and learn about the course content taught by our department. Web lectures can thus also serve as promotional material for the Department.

YouTube videos are usually presented in a rather haphazard way, as a list of topics. We gave the list structure:the name of the video coded (Dutch) name of the topic (GIS, KC or TI),; a number to indicate the order of the video and possibly the topic of the web lecture itself (e.g., TI_116_layers; KC_11_vanGeoNaarCart).

A separate website was created to facilitate topic reviews. This website contains links to videos on YouTube (see Figure 5). The URL of this webpage, (http://cartogis.ugent.be/weblectures/), was communicated to the students during class. Afterwards, they could find it on their online learning platform (http://minerva.ugent.be/).

On the main page of this website, an overview of all currently existing main topics of web lectures is presented. For each topic, a separate page was created, which lists the associated web lectures in a structured way. The web lectures for the subjects "Inl. Topo \& GIS" and "GIS Hydro" are derived from the GIS web lectures with certain specific applications and are taught in the second semester of the academic year. These will not be discussed here. 

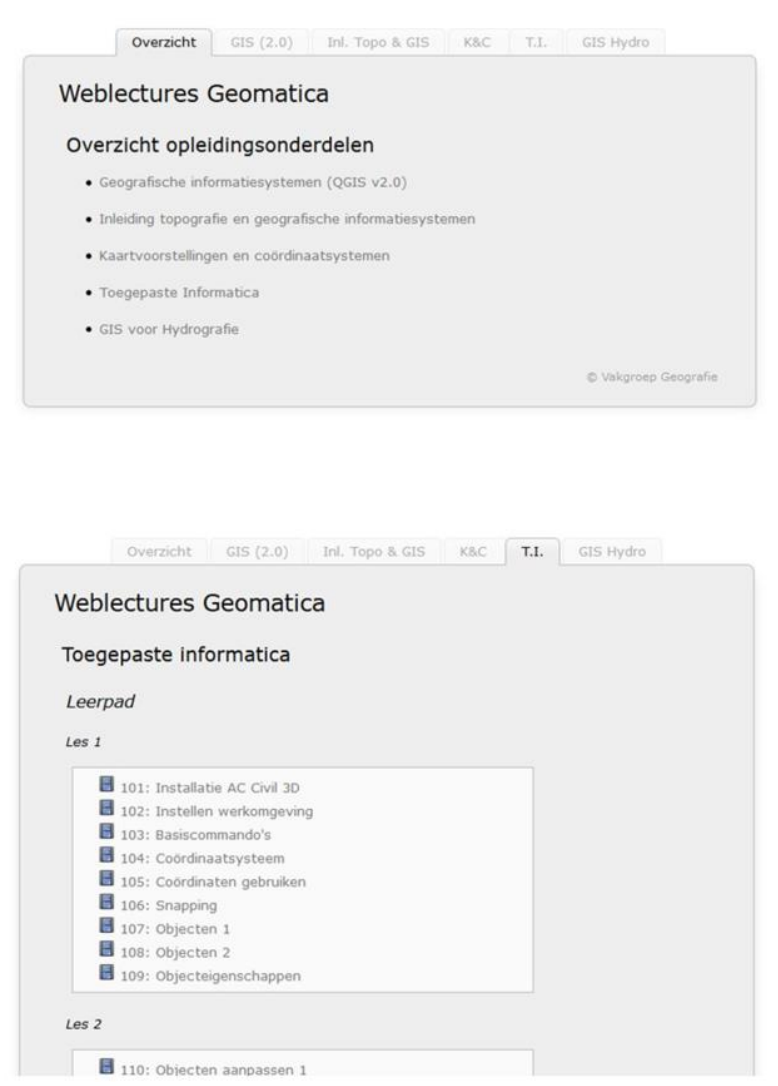
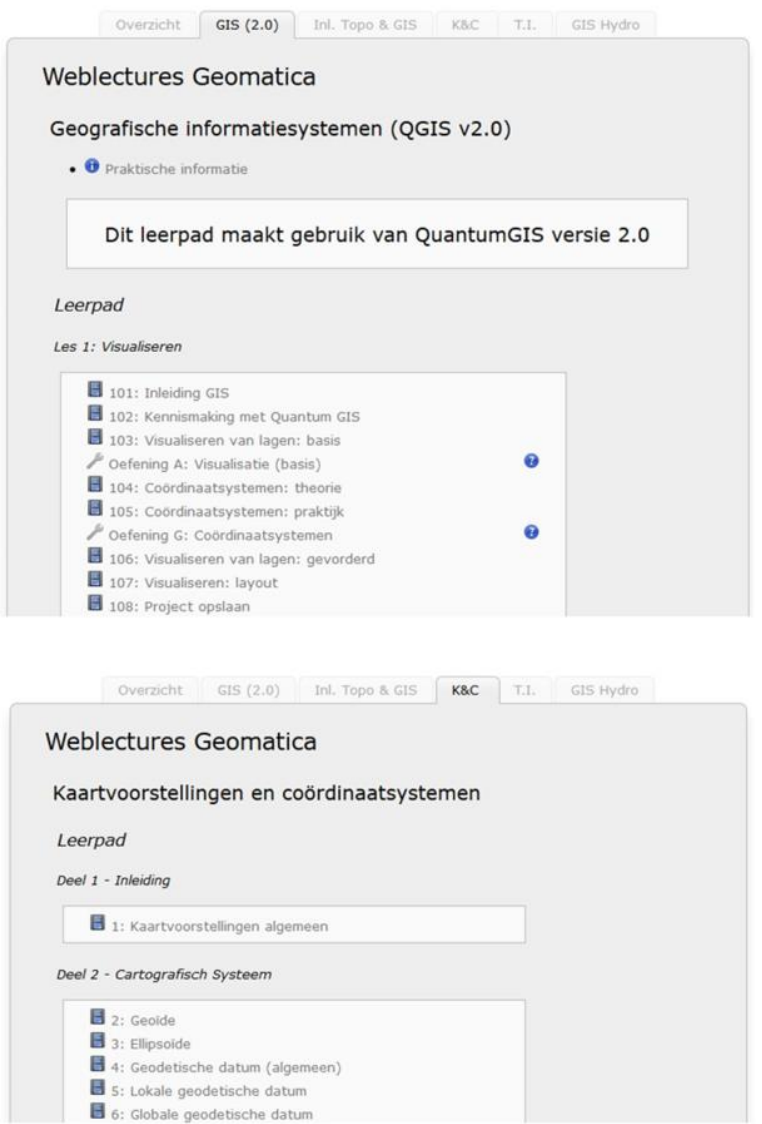

Figure 5. Online overview of existing web lectures.

We could have integrated our web lectures into the Learning Management System of the university( Minerva). However, because this method would only allow students enrolled at the university to have access to the web lectures, we decided not to upload to Minerva. Instead, we offer web lectures through our own website. We started with a simple web design, but, if requested by the students, we can integrate more tools and function in the website and so improve interactions. Feedback from the students evaluating the website suggests that the website could be expanded to cover more lectures.

\subsection{Applying User-Centered Design}

The success of web lectures is closely tied to how they are perceived by the students: i.e,, perceived ease of use, perceived usefulness, students' motivation, etc. (Davis et al. 1989; Liu et al. 2009). We therefore decided to focus on the web lectures' usability. We did that by implementing the UCD lifecycle on the initial set of web lectures which are evaluated by end users. Based on their feedback, the web lectures will then be improved and extended. By involving students in the design process, their perception of the system can be taken into account before the system becomes operational. The process and results of the initial evaluation are described in detail in the next section. 


\section{Evaluation of the web lectures}

\subsection{Feedback form}

The initial set of web lectures was evaluated by students using a feedback form. The same form was used for all topics and all students. The purpose of the evaluation was to obtain a better understanding of students' needs and how the available online lectures can be improved and extended to other topics . A two-page feedback form was handed out to students during the first semester's final exam of the courses for which web lectures were used (see Table 1). Students were instructed to fill out the form after completing the exam (so as not to interfere with the actual exam); even those students who had not used any web lecture were encouraged to respond. Two types of questions were asked: the first type were closed questions required a Yes or No answer; the second type were open questions. The answers provided by students were summarized and are discussed in the following sections.

\subsection{Results}

\subsubsection{Participants}

In total, 132 students filled out the feedback form. A detailed overview of the students who filled out the form is presented in Table 2 and Table 3, by course.

Table 2. Participants by course.

\begin{tabular}{|l|c|}
\multicolumn{1}{|c|}{ Course } & $\begin{array}{c}\# \\
\text { students }\end{array}$ \\
\hline Introduction Geomatics & 41 \\
\hline GIS & 40 \\
\hline Cartography & 28 \\
\hline Applied Informatics & 13 \\
\hline $\begin{array}{l}\text { Map Projections and } \\
\text { Coordinate Systems }\end{array}$ & 10 \\
\hline
\end{tabular}

Table 3. Participants by year and course of study.

\begin{tabular}{|l|c|}
\hline \multicolumn{1}{|c|}{ Year \& Study } & $\begin{array}{c}\# \\
\text { students }\end{array}$ \\
\hline 1e Ba Geography & 36 \\
\hline 2e Ba Geography & 20 \\
\hline 2e Ba Geography and Geomatics & 9 \\
\hline 2e Ba Archaeology & 4 \\
\hline 3e Ba Geography & 11 \\
\hline 3e Ba Geography and Geomatics & 8 \\
\hline 3e Ba Archaeology & 4 \\
\hline MSc Geography & 10 \\
\hline MSc Geomatics and Surveying & 12 \\
\hline MSc Biology & 7 \\
\hline MSc Archaeology & 1 \\
\hline PhD Archaeology & 1 \\
\hline
\end{tabular}

\subsubsection{Web Lecture Usage}

On the feedback form, students had to indicate whether they had used web lectures associated with the course for which they were taking the exam. The results for each course are presented in Figure 6. A clear distinction is shown between the first two courses and the other three: web lectures with software demonstrations or with theoretical lectures, respectively. To be able to explain this, students who had not utilized web lectures were asked to indicate why they chose not to. This is summarized in Table 4. 


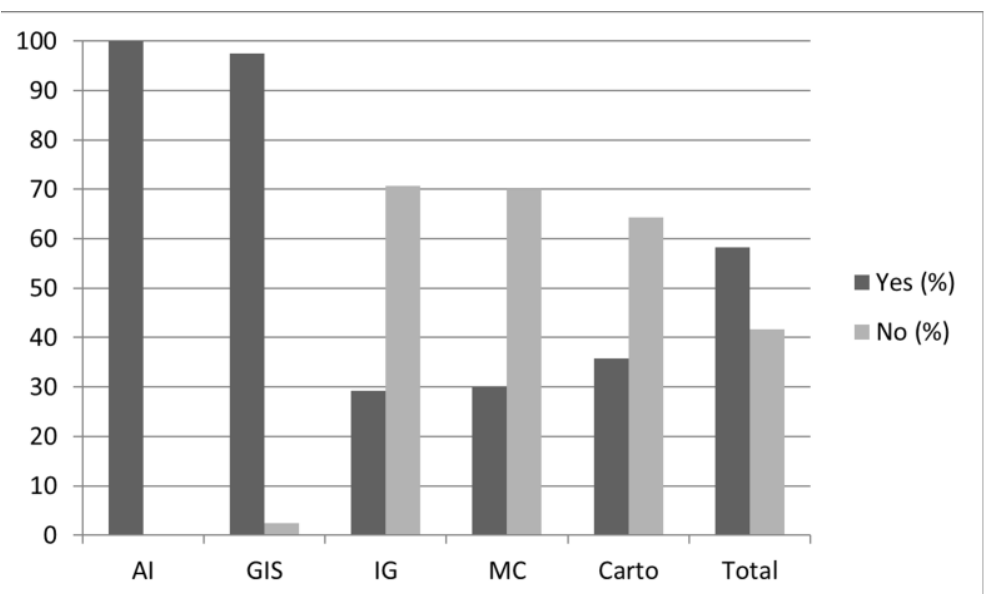

Figure 6. Percentage of students who did (or did not) use the available web lectures.

The reasons students gave could be explained by a difference in motivation for using practical or theoretical web lectures, as was mentioned by Day et al. (2005). For each practical session, a number of web lectures were available, and students were reminded of this. As a consequence, nearly all students watched all practical lectures. The existence and location of the web lectures for theoretical topics were communicated at the beginning of the first lesson and through the digital learning platform. However, students had not been reminded about the theoretical web lectures in subsequent sessions.

The students who used the web lectures were asked how they employed them. Because a clear distinction was noticed in the usage of "theoretical" and "practical" web lectures (see Figure 6), the results will be presented separately for each of the associated courses and summarized per type in Table 5.This table shows that all of the practical demonstrations were used, whereas for theoretical explanations, students tended to select web lectures on those topics they found difficult to process.

Table 4. Reasons for not using web lectures.

\begin{tabular}{|l|c|}
\hline \multicolumn{1}{|c|}{ Students' reactions } & \# mentioned \\
\hline "I did not know they existed" & 17 \\
\hline "I forgot about them" & 12 \\
\hline "I did not find them" & 11 \\
\hline "I did not need them" & 10 \\
\hline "I found them too late" & 3 \\
\hline "I prefer the book" & 2 \\
\hline TOTAL & $\mathbf{5 5}$ \\
\hline
\end{tabular}


Table 5. Students' rating of web lectures(/10).

\begin{tabular}{|l|c|c|c|c|c|c|c|}
\hline \multicolumn{1}{|c|}{ Students" reactions } & AI & GIS & $\begin{array}{c}\text { Total } \\
\text { Pract. } \\
(\%)\end{array}$ & IG & MC & Carto & $\begin{array}{c}\text { Total } \\
\text { Theor. } \\
(\%)\end{array}$ \\
\hline "all of them" & 11 & 38 & $\mathbf{9 6 . 1}$ & 1 & 0 & 3 & $\mathbf{1 7 . 4}$ \\
\hline $\begin{array}{l}\text { "only when I did not } \\
\text { understand" }\end{array}$ & 2 & 0 & $\mathbf{3 . 9}$ & 4 & 2 & 7 & $\mathbf{5 6 . 6}$ \\
\hline $\begin{array}{l}\text { "as an addition to the } \\
\text { course materials" }\end{array}$ & 0 & 0 & $\mathbf{0}$ & 1 & 1 & 0 & $\mathbf{8 . 7}$ \\
\hline "just tried them out" & 0 & 0 & $\mathbf{0}$ & 4 & 0 & 0 & $\mathbf{1 7 . 4}$ \\
\hline
\end{tabular}

\subsubsection{Good and bad points for the available web lectures}

Students were asked to rate the available web lectures on a scale from 1 to 10 . The average course rates are presented in Table 6 . The overall average was 8.17 out of 10 which indicates highly favorable perception of web lectures. However, no clear distinction can be made between the favorability of theoretical and practical web lectures. The evaluation results also indicate that students who are "external" to the Department of Geography (i.e., Archaeology and Biology students) do not necessarily give a lower or higher score to the web lectures,. Geography students, especially freshmen, tend to be most critical of web lectures.

Table 6. Overview of how students rate the available weblectures (/10)

\begin{tabular}{lrrrrr}
\multicolumn{1}{c}{ Course } & Arch & Bio & Geog & Geom & Total \\
AI & & & 7,60 & 8,56 & $\mathbf{8 , 1 9}$ \\
\hline GIS & 8,00 & 8,92 & 8,38 & 8,90 & $\mathbf{8 , 5 0}$ \\
\hline IG & 8,00 & & 6,95 & & $\mathbf{7 , 0 5}$ \\
\hline MC & & & & 8,67 & $\mathbf{8 , 6 7}$ \\
\hline Carto & 8,67 & & 7,50 & 8,00 & $\mathbf{7 , 9 5}$ \\
\hline Total & $\mathbf{8 , 2 9}$ & $\mathbf{8 , 9 2}$ & $\mathbf{7 , 8 8}$ & $\mathbf{8 , 5 8}$ & $\mathbf{8 , 1 7}$
\end{tabular}

In addition to scoring the web lectures, students could also indicate in an open question what they found positive about them. Their reactions are summarized in Table 7. One finding is that students appreciated the structured nature of the web lectures. They also liked the possibility of going through the topics at their own pace and the ability to repeat the lectures if necessary.

Students also had the opportunity to indicate in an open question where there was still room for improvement. Their reactions to this question are summarized in Table 8. Compared with positive comments, remarkably fewer suggestions for improvement were given (46 vs. 87). Most of the critique referred to "cut and paste" video editing errors in one of the web lectures for Applied Informatics in the "demonstrations in AutoCAD" series. Students also commented on the need for the practical web lectures to give more examples, particularly ins 
such fields as Biology and Archaeology. Some students found the web lectures too fast, others suggested increasing their speed.

Table 7. Beneficial aspects of web lectures.

\begin{tabular}{|l|c|}
\multicolumn{1}{|c|}{ Students' reactions } & \# mentioned \\
\hline "structures and/or clear" & 31 \\
\hline "possibility to pause, complete at own pace" & 18 \\
\hline "possibility to repeat topics" & 12 \\
\hline "it is always available" & 8 \\
\hline "possibility to obtain additional explanation" & 6 \\
\hline "useful when you cannot make it to class" & 2 \\
\hline "it can be used at home" & 2 \\
\hline "additional examples are given" & 2 \\
\hline "you can search for info in the demos" & 2 \\
\hline "it is more visual than a course" & 2 \\
\hline "you get more personal guidance" & 1 \\
\hline "they are complete" & 1 \\
\hline TOTAL & $\mathbf{8 7}$ \\
\hline
\end{tabular}

Finally, students were asked for their opinion of the website that delivers the web lectures. Most students found the website well-structured and easy to use (59 out of 64). Two students found the site confusing, one would appreciate more guidance, and one said the website was difficult to use at the beginning. One student mentioned that the web lectures linkage to YouTube was seen as a positive element.

Table 8. Suggested improvements.

\begin{tabular}{|l|r|}
\hline \multicolumn{1}{|c|}{ Students" reactions } & \# mentioned \\
\hline "improve cut/paste operations" & 6 \\
\hline "more demos with specific examples (e.g. biology)" & 5 \\
\hline "too fast" & 4 \\
\hline "more demos for a larger exercise/ solutions for exercises" & 4 \\
\hline "better intonation/fluency" & 3 \\
\hline "some are too long" & 3 \\
\hline "too slow" & 2 \\
\hline "more topics/subjects" & 2 \\
\hline "more background information on the demos" & 2 \\
\hline "demos: software needs to be updated" & 2 \\
\hline "additional documentation besides the demos (e.g. solutions)" & 2 \\
\hline "more details" & 1 \\
\hline "better quality" & 1 \\
\hline "integration into Minerva" & 2 \\
\hline
\end{tabular}




\begin{tabular}{|l|r|}
\hline "make them better known" & 1 \\
\hline "more practical weblectures" & 1 \\
\hline "make everything in ppt" & 1 \\
\hline "demos: show some typical errors" & 1 \\
\hline "all weblectures should be available at the beginning of the semester" & 1 \\
\hline "make all demos uniform in structure" & 1 \\
\hline "make a demo for the assignments" & $\mathbf{4 6}$ \\
\hline TOTAL &
\end{tabular}

\subsubsection{Suggestions for creating additional web lectures}

All students, even those who had not used the available web lectures, were asked whether they would find it useful to extend the number of web lectures. A distinction was made between web lectures for theoretical (th) and for practical (pr) purposes. The results are presented in Figure 7. Most students were in favor of an extension of the current offer of web lectures, both for theoretical and practical purposes. However, more than $50 \%$ of GIS students said they did not believe that web lectures should be extended for theoretical purposes. Similar results were obtained for practical web lectures when probing students in the Introduction to Geomatics class. These results may be linked to the (lack of) perceived usability of these types of web lectures (e.g. Davis et al. 1989; Liu et al. 2009).

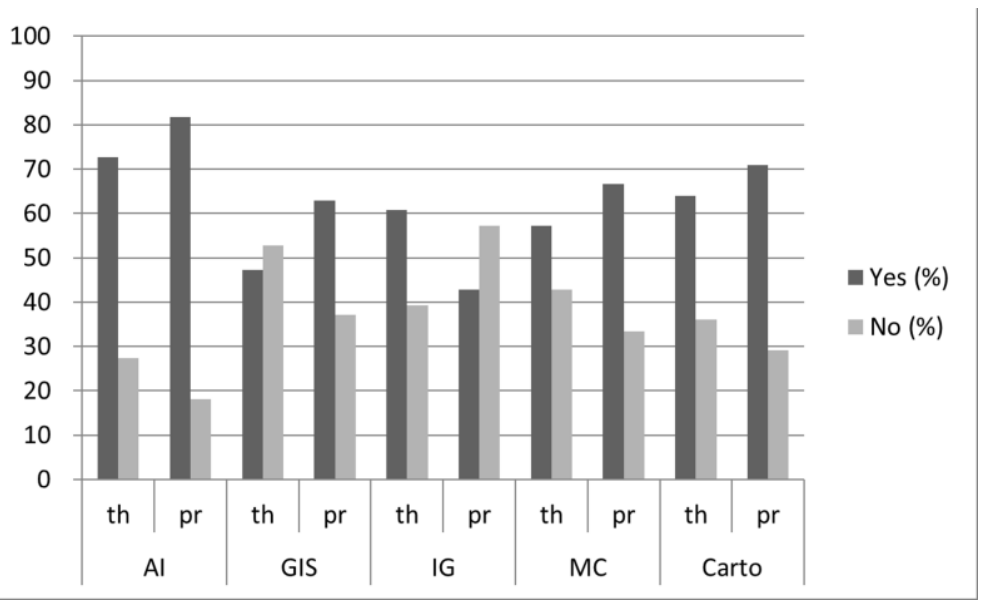

Figure 7. Percentage of students who would appreciate having more web lectures.

Students were asked for which subjects they would like to have web lectures, particularly with regard to theoretical and practical subjects. A list of potential topics was proposed, but students could still write down their own suggestions. Table 9 shows the results. Most students requested theoretical and practical web lectures about "spherical trigonometry". Many students also said they would find web lectures on ArcGIS very useful, both theoretical and practical. "Topographic representations" was another topic often mentioned for theoretical web lectures. Some students indicated that any topic would be welcome, or that the focus should be on the most difficult topics. Topography was mentioned by a large number of students in the category of practical web lectures. 
Table 9. Suggestions of topics for future web lectures.

\begin{tabular}{|l|c|c|}
\hline \multicolumn{1}{|c|}{ Topic } & \# theoretical & \# practical \\
\hline Spherical trigonometry & 16 & 9 \\
\hline Topographic representations & 10 & 0 \\
\hline Demos ArcGIS & 9 & 17 \\
\hline As many as possible & 9 & 1 \\
\hline Difficult topics & 7 & 0 \\
\hline Colour & 6 & 3 \\
\hline Introduction to exercises & 4 & 5 \\
\hline Generalization & 4 & 2 \\
\hline Astronomy & 3 & 0 \\
\hline Topography & 3 & 10 \\
\hline Parts of the map & 2 & 2 \\
\hline GIS applications & 2 & 2 \\
\hline AutoCAD 3D (Civil) & 2 & 2 \\
\hline Discretisation & 1 & 5 \\
\hline Modelling & 1 & 0 \\
\hline Topology & 1 & 0 \\
\hline Anything cartographic & 1 & 0 \\
\hline Basic skills & 1 & 0 \\
\hline Demos (general) & 0 & 6 \\
\hline Extend demos QGIS & 0 & 5 \\
\hline Solutions of exercises & 0 & 2 \\
\hline Physical geography & 0 & 2 \\
\hline Coordinate transformations & 0 & 1 \\
\hline Practical exercises in physics & & 1 \\
\hline
\end{tabular}

\subsubsection{Comparison web lectures versus traditional lectures}

Students were asked to compare the value of web lectures against that of live lessons and whether web lectures could replace live lessons. Table 8 shows that students found both the theoretical and practical web lectures of great value. Nonetheless, most students thought that web lectures cannot replace in-person lectures.

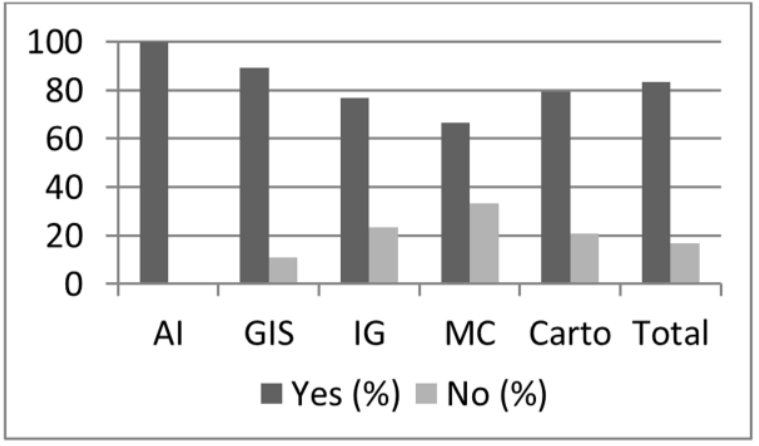

(a)

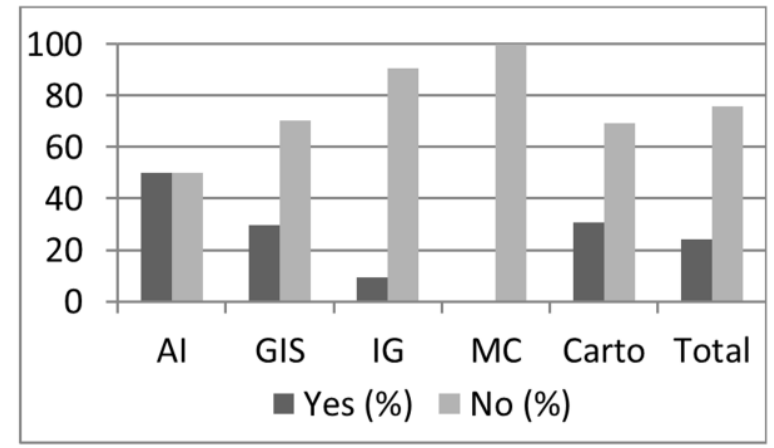

(b)

Figure 8. Students' opinion on the added values of web lectures compared to traditional lectures $(a)$ and whether online lectures could replace traditional lectures $(b)$. 
The majority of students gave the same reason why web lectures cannot replace traditional lectures: lack of interaction, and most importantly, inability to ask questions (see Table 10). "Need for guidance," which was mentioned in relation to practical web lectures, echoes the need to be able to ask questions.. Students also attach high importance to personal communication which is less effective or efficient through web lectures. Using web lectures as a complement to the traditional lectures is the best of both worlds.

Table 10. Why web lectures cannot replace traditional lectures.

\begin{tabular}{|l|c|}
\hline "Students' reaction & 44 \\
\hline "track of interaction - ask questions" & 13 \\
\hline "it is ok if used complementary" & 8 \\
\hline "need for guidance" & 7 \\
\hline "lack of the social aspect" & 4 \\
\hline "things are approached differently in a traditional lecture" & 4 \\
\hline "pressure to attend lectures" & 4 \\
\hline "traditional lectures are the basis" & 3 \\
\hline "weblectures will replace traditional lectures" & 3 \\
\hline "it is ok if we can ask question via mail" & 3 \\
\hline "traditional lectures have an added value" & 2 \\
\hline "it's more difficult to keep your attention" & 2 \\
\hline "weblectures suffice" & 2 \\
\hline "more difficult to take notes" & 1 \\
\hline "fellow students are important" & 1 \\
\hline "lecturer has to do something" & 1 \\
\hline "structure of lessons, blackboard schedules are lacking" & 1 \\
\hline "there is no physical class" & 1 \\
\hline "it is only ok for practical topics" & 1 \\
\hline
\end{tabular}

\subsubsection{Influence on student achievement}

As important as students' motivation and acceptance of web lectures are, the level of student achievement also plays an important role in the development of web lectures. However, theoretical web lectures had only been introduced for one chapter of the course, and students indicated that they did not use them regularly. This suggests their exam results would not have been significantly influenced by web lectures. The practical QGIS web lectures have been used for several years, which makes it possible to compare between students' performance before and after the introduction of web lectures. Before the introduction of web lectures, the average score on the practical exam was 12.09/20 for the period 2008 to 2011. After the introduction of web lectures, the average score rose to $13.30 / 20$ from 2012 to 2014. However, care has to be taken when interpreting these results because other factors also changed in this period, which could influence students' results (e.g., ArcGIS was previously taught with an examination on paper; QuantumGIS is now used with an examination on a $\mathrm{PC})$. 


\section{Discussion}

The high, overall score of $8.17 / 10$ suggests that the students had a positive attitude regarding the web lectures on offer. The level of students' background knowledge does not seem to influence exam scores. Archaeology and Biology students did, however, ask for more demonstrations with field-specific examples. All students e appreciated the clear structure of the videos and the possibility to study at their own pace. Still, students need to be motivated to use web lectures: they should be reminded that they exist and where they can be found. This corresponds to the findings of Day et al. (2005). A number of students also indicated that while traditional lectures are closely associated with pressure to attend them, web lectures require more discipline to study (Moses et al. 2002; Day et al. 2005; Day \& Foley 2006). However, practical web lectures with software demonstrations were all used by nearly every student. Even though online demonstrations replaced in-class demonstrations, students could, ask for guidance or questions, keeping the social aspect of the educational process intact. The practical web lectures received an above-average score from the students, confirming that they were appreciated. The students' positive and negative comments on both types of web lectures were similar; however, as the practical web lectures were used more, most comments apply to practical web lectures.

Most students recognize the added value of web lectures, but do not think they can replace traditional lectures. They find it important to be able to ask questions and have personal guidance. This is closely related to the social aspect and added value of face-to-face contact with the teacher and among students (Calverley et al. 1998; Rafaeli et al. 2004; Day et al. 2005; Day \& Foley 2006; Chen et al. 2010). Students were in favor of extending the current set of web lectures for both theoretical and practical topics. The suggested topics and their rankings are the basis of a priority list to create more web lectures in the future. Often requested were practical web lectures on Topography. These are not software demonstrations but demonstrations by a teacher on how to use certain equipment (e.g., how to level surveying equipment or working with advanced GPS-devices). Possibly, the existing website could also be enhanced, creating a more interactive learning environment.

The number of in-class meetings for the practical GIS sessions was reduced. As students only came to the sessions if they had questions, fewer students were present in class, who thus received more individual guidance and feedback (Twigg 2001, 2003; Roberts \& Dyer 2005a, 2005b). The students perceived this as an important asset of the blended learning strategy. Attendance was not perceived to be lower because of the theoretical web lectures, possibly because these web lectures do not aim to replace traditional live lectures but should be used as complements. The public availability of the web lectures was found to be major asset to the university, as they are an easy way to showcase the University and the courses it offers to potential students.

Very few problems were discovered in the design of the initial set of web lectures and the associated website. Almost no existing web lectures need to be improved. The focus for the future can thus be directed on the development of additional web lectures based on a similar concept.

Two teachers were involved in the creation of the web lectures. However, their number may increase as the number of topics covered by the web lectures increases. Teachers can decide if they want to create web lectures and integrate them into their courses. 
Not all persons may be in favor of being recorded and placing the resulting videos online with public availability. This could thus be a limiting factor in the creation of web lectures for certain topics. The development of web lectures is supported by our faculty (Faculty of Sciences, Ghent University), which means that funds are available to support departments that invest in the integration of many types of web lectures into their curriculum.

\section{Conclusion \& Future Work}

The initial set of web lectures was created for students who follow GIS-related courses at the Department of Geography at Ghent University. The evaluation of the lectures indicated that students appreciate the blended learning strategy because with web lectures complementing traditional lectures and practical exercises, more in-class time can be spent to address specific questions, to give feedback and for personal guidance. Students attached high importance to the social aspect of learning, which is missing when only web lectures are utilized. However, many students need to be motivated to use especially the theoretical web lectures. Through the application of UCD, issues like this can be discovered at an early stage in the development of novel concepts, such as these web lectures. Consequently, this finding will be further investigated during the next phase of the User-Centered Design lifecycle. Few design issues were discovered at this initial stage, which means none of the existing web lectures need to be adapted. Future effort should thus focus on the development of additional web lectures based on a similar concept (layout, length, posted on YouTube, website with overview, etc.) as the existing weblectures, since this has been approved by the students. A priority list of topics can be constructed for which the highest need was expressed by the students. With every subsequent year, the students' perception towards the web lectures will be evaluated further.

\section{References}

Allen, B. S., Otto, R. G., \& Hoffman, B. (1996). Media as lived environments: The ecological psychology of educational technology. Handbook of research for educational communications and technology, 2, 215-241.

Antrop, M., De Maeyer, P., Van de Weghe, N., \& Neutens, T. (2013). Geografische informatiesystemen. Ghent: Academia Press.

Bernard, R. M., Abrami, P. C., Lou, Y. P., Borokhovski, E., Wade, A., Wozney, L., Wallet, P. A., Fiset, M., \& Huang, B. R. (2004). How does distance education compare with classroom instruction? A meta-analysis of the empirical literature. Review of Educational Research, 74(3), 379-439.

Calverley, G., Fincham, D., \& Bacon, D. (1998). Modernisation of a traditional physics course. Computers \& Education, 31(2), 151-169.

Chandler, T., Park, Y. S., Levin, K. L., \& Morse, S. S. (2013). The incorporation of hands-on tasks in an online course: an analysis of a blended learning environment. Interactive Learning Environments, 21(5), 456-468.

Chen, P. S. D., Lambert, A. D., \& Guidry, K. R. (2010). Engaging online learners: The impact of Web-based learning technology on college student engagement. Computers \& Education, 54(4), 1222-1232.

Clark, R. E. (2009). Past and future research in online education. Proceedings of annual meeting of the American Education Research Association.

Dale, E. (1969). Audio-visual methods in teaching (Vol. 108): Dryden Press New York. 
Davis, F. D., Bagozzi, R. P., \& Warshaw, P. R. (1989). User Acceptance of ComputerTechnology - a Comparison of 2 Theoretical-Models. Management Science, 35(8), 982-1003.

Day, J. A. (2008). Investigating learning with web lectures.

Day, J. A., \& Foley, J. D. (2006). Evaluating a Web lecture intervention in a human-computer interaction course. Ieee Transactions on Education, 49(4), 420-431.

Day, J. A., Foley, J. D., Groeneweg, R., \& Van der Mast, C. (2005). Enhancing the classroom learning experience with Web lectures. Proceedings of International Conference on Computers in Education, Singapore.

De Maeyer, P., De Wulf, A., Neutens, T., \& Ooms, K. (2013). Geomatica voor Geologen. Een inleiding tot topografie, GIS en cartografie. Ghent: Academia Press.

De Maeyer, P., De Wulf, A., \& Van de Weghe, N. (2012). Basisbegrippen Geomatica. Ghent: Academia Press.

De Maeyer, P., \& Ooms, K. (2013). Cartografie. Ghent: Academia Press.

Dori, Y. J., Barak, M., \& Adir, N. (2003). A Web-based chemistry course as a means to foster freshmen learning. Journal of Chemical Education, 80(9), 1084-1092.

Earthy, J., Jones, B. S., \& Bevan, N. (2001). The improvements of human-centred processes facing the challenge and reaping the benefit of ISO 13407. International Journal of Human-Computer Studies, 55, 553-585.

Eveland, W. P., \& Dunwoody, S. (2001). User control and structural isomorphism or disorientation and cognitive load? Learning from the Web versus print. Communication Research, 28(1), 48-78.

Frigerio, S., \& van Westen, C. J. (2010). RiskCity and WebRiskCity: Data Collection, Display, and Dissemination in a Multi-Risk Training Package. Cartography and Geographic Information Science, 37(2), 119-135.

Garrison, D. R., \& Kanuka, H. (2004). Blended learning: Uncovering its transformative potential in higher education. The internet and higher education, 7(2), 95-105.

Harvey, F., \& Kotting, J. (2011). Teaching Mapping for Digital Natives: New Pedagogical Ideas for Undergraduate Cartography Education. Cartography and Geographic Information Science, 38(3), 269-277.

Ketterl, M., Mertens, R., \& Vornberger, O. (2009). Bringing web 2.0 to web lectures. Interactive Technology and Smart Education, 6(2), 82-96.

Lee, L.-S., Lin, K.-Y., Guu, Y.-H., Chang, L.-T., \& Lai, C.-C. (2013). The effect of hands-on 'energy-saving house'learning activities on elementary school students' knowledge, attitudes, and behavior regarding energy saving and carbon-emissions reduction. Environmental Education Research, 19(5), 620-638.

Lee, M. G. (2001). Profiling students' adaptation styles in Web-based learning. Computers \& Education, 36(2), 121-132.

Liu, S. H., Liao, H. L., \& Pratt, J. A. (2009). Impact of media richness and flow on e-learning technology acceptance. Computers \& Education, 52(3), 599-607.

McMaster, S., Edsall, R., \& Manson, S. (2011). Geospatial Research, Education and Outreach Efforts at the University of Minnesota. Cartography and Geographic Information Science, 38(3), 335-337.

Moses, G., Litzkow, M., Foertsch, J., \& Strikwerda, J. (2002). eTeach®-a proven learning technology for education reform. Proceedings of Frontiers in Education, 2002. FIE 2002. 32nd Annual.

Nielsen, J. (1993). Usability Engineering. San Francisco: Morgan Kaufmann.

Parkinson, T. M., Force, J. E., \& Smith, J. K. (2003). Hands-on learning: Its effectiveness in teaching the public about wildland fire. Journal of Forestry, 101(7), 21-+. 
Poindexter, S. E., \& Heck, B. S. (1999). Using the Web in your courses: What can you do? What should you do? Control Systems, IEEE, 19(1), 83-92.

Rafaeli, S., Barak, M., Dan-Gur, Y., \& Toch, E. (2004). QSIA - a Web-based environment for learning, assessing and knowledge sharing in communities. Computers \& Education, 43(3), 273-289.

Roberts, T. G., \& Dyer, J. E. (2005a). The influence of learning styles on student attitudes and achievement when an illustrated web lecture is used in an online learning environment. Journal of agricultural education, 46(2), 1-11.

Roberts, T. G., \& Dyer, J. E. (2005b). The relationship of self-efficacy, motivation, and critical thinking disposition to achievement and attitudes when an illustrated web lecture is used in an online learning environment. Journal of agricultural education, 46(2), 12-23.

Sitzmann, T., Kraiger, K., Stewart, D., \& Wisher, R. (2006). The comparative effectiveness of web-based and classroom instruction: A meta-analysis. Personnel Psychology, 59(3), 623-664.

Tiellet, C. A., Pereira, A. G., Reategui, E. B., Lima, J. V., \& Chambel, T. (2010). Design and evaluation of a hypervideo environment to support veterinary surgery learning. Proceedings of 21 st ACM conference on Hypertext and hypermedia.

Twigg, C. A. (1999). Improving Learning and Reducing Costs: Redesigning LargeEnrollment Courses.

Twigg, C. A. (2001). Innovations in online learning. Proceedings of Moving beyond no significant difference. The PEW Learning and Technology Program.(symposium monograph). Troy, NY: Center for Academic Transformation. Rensselaer Polytechnic Institute.

Twigg, C. A. (2003). Models for online learning. Educause review, 28-38.

van Elzakker, C. P. J. M., \& Wealands, K. (2007). Use and users of multimedia cartography. In W. Cartwright, M. Peterson\&G. Gartner (Eds.), Multimedia cartography (pp. 487504). Berlin Heidelberg: Springer.

Ward, M., \& Newlands, D. (1998). Use of the Web in undergraduate teaching. Computers \& Education, 31(2), 171-184. 